Federal Reserve Bank of Minneapolis

Research Department Staff Report 194/JV

\title{
Fixed vs. Floating Exchange Rates: A Dynamic General Equilibrium Analysis*
}

\author{
Daniel M. Chin and Preston J. Miller \\ Federal Reserve Bank of Minneapolis
}

\begin{abstract}
In this study we contrast fixed and floating exchange rate regimes in a dynamic general equilibrium model. We find that the fundamental difference in the regimes is in the courses they imply for monetary policies. Because of policy coordination requirements, a tighter monetary policy needed to maintain a fixed exchange rate may necessitate a tightening in budget policy as well. We show that under some initial conditions voters or a social planner will favor one regime, but under other conditions they will favor the other. However, the choices of voters and a social planner are almost diametrically opposed.

*The views expressed herein are those of the authors and not necessarily those of the Federal Reserve Bank of Minneapolis or the Federal Reserve System.
\end{abstract}


What causes differences in macroeconomic outcomes under floating and fixed exchange rate regimes? Why do citizens of a country sometimes favor one regime and at other times favor the other? In this paper we construct a dynamic general equilibrium model to address these questions. Our analysis can be considered a microeconomic foundation for the monetary approach to the balance of payments. (See, for example, Frenkel and Mussa 1985). As with that approach, our analysis attributes differences in macroeconomic outcomes under fixed and floating exchange rates to the differences in monetary policies they imply. In addition, our analysis finds that differences in monetary policies can require differences in government budget policies to make the two mutually sustainable. $^{1}$

In our model monetary policy has real and distributional effects, and hence, the choice of exchange rate regime also has these effects. In particular, a more restrictive monetary policy helps agents in some sectors but hurts those in others. However, in our model the number of agents in each sector can change over time as agents respond to new economic conditions. The change in the allocation of agents across sectors then makes possible a shift in the majority favoring a particular exchange rate regime.

Basic to our model's analysis of exchange rate regimes is the nonneutrality of monetary policy. The nonneutrality stems from an assumption of legal restrictions which take the form of reserve requirements. The legal restrictions provide a coherent and convenient explanation for the existence of separate demands for country-specific fiat monies and for fiat money and fiat bonds. ${ }^{2}$ Very importantly, the legal restrictions are a real friction. Because of this friction, monetary policy actions that alter the relative supplies of a country's money and bonds (for example, open-market operations) affect real magnitudes. Although the real-world relevance of the legal restrictions friction is open to debate, it does seem that some real frictions must be operating to explain the existence of separate demands for alternative fiat monies and separate demands for fiat monies and fiat bonds. 
Most of the logic of the legal restrictions theory would seem to flow just as long as some such real frictions exist.

The model is a direct extension of Miller and Todd (1995), which examined monetary policy effects under floating exchange rates. It was argued in the earlier paper that the dynamic international effects of a change in a major country's monetary policy are broadly consistent with observations. For instance, a sustained tightening in, say, U.S. monetary policy, all other countries' policies held constant, leads in the Miller-Todd model to:

- A sustained rise in the world real interest rate and the U.S. nominal interest rate,

- An initial rise in the nominal and real exchange value of the U.S. dollar, followed by a fall in each, and

- An initial move toward deficit in the U.S. current account balance followed by a move towards surplus.

Since the logic of the current model and analysis rely directly on that of Miller and Todd (1995), it is important to understand how that model generates the nominal and real effects described above. That model has two countries, "home" and "foreign," each with a public and a private sector. The public sector has a budget authority that taxes, spends, and borrows and a monetary authority that engages in open-market operations and imposes a reserve requirement against private savings. The requirement can be thought of as applying to deposits when all borrowing and lending is intermediated through banks. The private sector has overlapping generations of two-period-lived agents who reside in one of two sectors. In one sector agents are endowed with a nontraded good, and they tend to save. In the other sector agents are endowed with a traded good, and they tend to borrow. There are no bequests. All debt, public and private, is perfectly substitutable and is traded 
in a world capital market. Money is held solely in the country that issues it and solely to satisfy the reserve requirement.

The effects of a monetary policy change stem from six key features of the model..$^{3}$ These features are likely to be shared in a much broader class of models than those with legal restrictions:

1. There are no bequests, so that Ricardian equivalence does not hold. Thus, an increase in the world's supply of debt increases the world's real interest rate.

2. Some agents hold nominal outside wealth in the initial period. A policy change that affects the initial price level then affects real wealth and, thereby, other real variables.

3. The presence of nontraded goods allows international shifts in wealth to affect relative prices and real exchange rates (similar to the transfer problem discussed with reference to static models).

4. Strict monetarism holds in the sense that a country's price level is in fixed proportion to its money stock at all times. (Actually, this is strictly true as long as relative prices are unchanging. Otherwise, the model's feature is that the price of the traded good is in fixed proportion to the money stock.)

5. Unpleasant monetarist arithmetic prevails in the sense that an open-market sale at date $t$ raises the rate of inflation at date $t+1$ forward. ${ }^{4}$ This follows because the sale implies more government bonds outstanding at a higher real interest rate, and so more seignorage is required to meet the increased interest payments on government bonds.

6. A real friction in the form of a reserve requirement drives a wedge between the world real interest rate that borrowers pay and the lower real rate of return that savers receive.

Miller and Todd analyze monetary policy effects under floating exchange rates, but they cannot explore why countries sometimes choose floating exchange rates and other times choose fixed. 
Miller and Todd assume an endowment economy with fixed numbers of agents over time in each sector. These assumptions imply that a monetary policy change will permanently raise the utility of agents in one sector, while permanently lowering the utility of agents in the other. Thus, society's preference for one exchange rate regime over the other will be the same over all time.

In this paper we modify the Miller-Todd model to overcome those difficulties. We introduce production in a special way to replace endowments. We assume production functions that have decreasing returns to labor but generate output bundles analogous to the Miller-Todd endowment patterns when the number of workers in each sector is held fixed. We allow agents to choose onceand-for-all when they first come on the scene in which sector they wish to work. With perfect foresight, their choice is made based on the expected utility derived in either sector.

Our assumptions about production are very special. It is reasonable to ask why they were made and to what extent they restrict the model's implications.

The reason for the production assumptions is basically mathematical convenience. The production technologies are specified so that for fixed labor market allocations the production economy is identical to the Miller-Todd endowment economy. In general the production model would be difficult to solve, and its equilibria's existence and uniqueness properties would be difficult to ascertain. However, these difficulties were overcome in the Miller-Todd endowment economy. The correspondence of production patterns in our model to the Miller-Todd endowment patterns is critical in our ability to solve the production model. In addition in the current paper we assume decreasing returns to the labor input, so that changes in the relative returns of working in the two sectors would not result in all of labor shifting to one sector. That is, with decreasing returns some labor will be employed in each sector.

Thus, in order to judge how restrictive our production assumptions are, one must judge how restrictive our endowment assumptions are. On an intuitive level we argue that none of the six key 
features of the model depends on endowment patterns. We argue then that our implications depend primarily on other features of our model. On a more formal level we recognize that our equilibrium requires a positive amount of internal borrowing and lending and a positive real interest rate in equilibrium. We accomplish this by giving one group a relatively large first-period endowment and relatively small second-period endowment (lenders) and by giving the other group the opposite pattern (borrowers). Within this general set-up we make two specialized assumptions. First, we assume that lenders' second-period endowment is not just relatively small-it is in fact zero. It is this assumption coupled with log-linear utility that allows us to solve the model forward period-byperiod. In general, agents' actions today would depend on the whole pattern of prices into the indefinite future. They don't in our model because of the zero endowment assumption. Yet, because of continuity of the solutions with respect to once-and-for-all changes in policy parameters, we know that our qualitative policy results would not be changed for sufficiently small, positive second-period endowments for lenders.

Second, we equate borrowers with world traders and lenders with providers of the nontraded good. One might ask what if instead we had made the world traders the lenders and the nontraded goods providers the borrowers. It is direct from Miller and Todd that the positive effects of a policy change would not be affected but the normative effects would be. Without loss of generality we can assume there are an equal number of agents in each sector (the numbers just scale the individual endowments). Miller and Todd show that in each sector individual demand functions are scalars (possibly dependent on borrowing/lending status, as in our individual demand functions) times the individual's present value of wealth. Reversing the endowment patterns then just reverses the demand functions. But since market excess demand functions depend on the sum of individual demand functions from each sector, the market excess demand functions remain unchanged because the sum of individual demand functions remains unchanged. However, who benefits and who loses 
from a change in policy will change. For instance, borrowers are hurt by a policy change which raises the real interest rate and lenders are helped, so it certainly matters which group is doing the borrowing and which is doing the lending. While this point cannot be denied, the main normative implications of this paper just require that a change in monetary policy affects differently the welfare of agents in the two sectors.

In addition to modifying Miller and Todd to allow production and labor mobility, we needed to allow for fixed exchange rates. We move from the floating exchange regime of Miller and Todd to a fixed exchange rate regime by a simple interchange of a few exogenous and endogenous variables with no changes to the other variables or equations. For the floating exchange rate system, we take as exogenous the variable which indicates foreign monetary policy and solve for the price of the foreign-produced traded good. For the fixed exchange rate system, we set the price of the foreign-produced traded good equal to the exogenous nominal exchange rate times the price of the domestic-produced traded good and solve for the foreign monetary policy indicator. We thus assume for the fixed exchange rate regime that the foreign economy pegs the value of its currency to the value of the home currency.

We note that our characterization of a pegged exchange rate system includes no role for central bank holdings of foreign reserves-something we observe in practice. Our model has no role for foreign reserves, because we consider only long-term changes in policy which are required when economic conditions change in a persistent and known way. In the real world foreign reserves are held because changes in economic conditions can be temporary and not well-recognized. Some foreign reserves then are held for precautionary motives. They allow a country to maintain a fixed nominal exchange rate without changing its monetary policy when shocks are temporary and, perhaps, reversed later. More importantly, in the real world the foreign reserves provide the mechanism that forces countries to change their macro policies when shocks prove to be long-lasting 
in effect. For example, suppose conditions change, but a country initially attempts to maintain its pegged exchange rate without changing its macro policies. The policies then are not consistent with its exchange rate, and this shows up as inflows or outflows of foreign reserves. It is the loss, or gain, of foreign reserves that eventually drives the country to change its policies. In our model countries are assumed to immediately change their policies to a sustainable course, because the shocks are permanent in effect and immediately known.

In the text that follows we first describe the model and solution for floating exchange rates. We then indicate how the model and solution are altered for fixed exchange rates. We next compare differences in outcomes for macroeconomic variables and distributions of welfare under the two exchange rate systems with respect to unanticipated changes in the model's parameters. Based on that analysis, we describe a numerical example which shows how voters or a social planner could prefer one system given one set of initial conditions but the other system given another set of initial conditions. We conclude with a discussion of some of the model's limitations and some ways to address them.

The Model

We briefly describe the model in this section. A more complete discussion is in the work of Miller and Todd (1992 and 1995).

\section{A. Structure}

In our model we consider two economies: home and foreign. Both have a private sector and a public sector. Both are populated by overlapping generations of agents who live two periods. At each integer date $t$ a new generation, generation $t$, appears. Agents born in date $t$ are referred to as generation $t$, and are young in date $t$ and old in date $t+1$. 
Each generation is populated by a constant number of individuals. Without loss of generality, we set the number in each generation equal to 1 . Upon arriving on the scene, individuals choose to work in one of the two sectors over their whole lifetimes.

All individuals in the global economy have identical preferences. The preferences are assumed to be represented by a discounted log-linear utility function, U, over service and food consumption in the two periods of an individual's life:

$$
\begin{aligned}
\mathrm{U}\left(\mathrm{c}_{\mathrm{t}}\right) & \equiv \mathrm{U}\left(\mathrm{c}_{\mathrm{t}}^{\mathrm{s}}(\mathrm{t}), \mathrm{c}_{\mathrm{t}}^{\mathrm{F}}(\mathrm{t}), \mathrm{c}_{\mathrm{t}}^{\mathrm{s}}(\mathrm{t}+1), \mathrm{c}_{\mathrm{t}}^{\mathrm{F}}(\mathrm{t}+1)\right) \\
& =\theta \log \mathrm{c}_{\mathrm{t}}^{\mathrm{s}}(\mathrm{t})+(1-\theta) \log \mathrm{c}_{\mathrm{t}}^{\mathrm{F}}(\mathrm{t})+\delta\left[\theta \log \mathrm{c}_{\mathrm{t}}^{\mathrm{s}}(\mathrm{t}+1)+(1-\theta) \log \mathrm{c}_{\mathrm{t}}^{\mathrm{F}}(\mathrm{t}+1)\right]
\end{aligned}
$$

where

$S$ is services, and $F$ is food,

$\theta$ is a parameter reflecting relative preferences for services versus food,

$\delta$ is a parameter reflecting the rate of time preference,

a subscript $t$ refers to a member of generation $t$,

and

an integer in parentheses is a date.

The preferences are taken to be the same in both economies, but the production and policy parameters, and hence prices and allocations, can differ between the two. To distinguish the economies, we use a superscript asterisk on foreign variables or functions. For example, foreign preferences are represented by $U\left(c_{t}^{*}\right)$.

Production is assumed to be a function of labor input with decreasing returns. The fraction of the young at time $t$ who choose work in farming is $n(t)$, so that $1-n(t)$ is the fraction who choose to work in services. The production technology is specified so that as long as $n(t)$ is fixed, 
the production economy mirrors the endowment economy of Miller and Todd (1995). In particular, we assume that the total output in sector $i$ at time $t$ from workers of generation $j, Y_{j}^{i}(t)$, is given by

$$
\begin{aligned}
& \mathrm{Y}_{\mathrm{t}}^{\mathrm{s}}(\mathrm{t}) \equiv(1-\mathrm{n}(\mathrm{t})) \mathrm{X}_{\mathrm{t}}^{\mathrm{s}}(\mathrm{t}) \equiv(1-\mathrm{n}(\mathrm{t})) A(1-\mathrm{n}(\mathrm{t}))^{\mathrm{a}-1}=A(1-\mathrm{n}(\mathrm{t}))^{\mathrm{a}}, \quad 0<\mathrm{a}<1 \\
& \mathrm{Y}_{\mathrm{t}}^{\mathrm{s}}(\mathrm{t}+1) \equiv(1-\mathrm{n}(\mathrm{t})) \mathrm{X}_{\mathrm{t}}^{\mathrm{s}}(\mathrm{t}+1)=0 \\
& \mathrm{Y}_{\mathrm{t}}^{\mathrm{F}}(\mathrm{t}) \equiv \mathrm{n}(\mathrm{t}) \mathrm{X}_{\mathrm{t}}^{\mathrm{F}}(\mathrm{t}) \equiv \mathrm{n}(\mathrm{t}) B \mathrm{n}(\mathrm{t})^{\mathrm{b}-1}=B \mathrm{n}(\mathrm{t})^{\mathrm{b}}, \quad 0<\mathrm{b}<1 \\
& \mathrm{Y}_{\mathrm{t}}^{\mathrm{F}}(\mathrm{t}+1) \equiv \mathrm{n}(\mathrm{t}) \mathrm{X}_{\mathrm{t}}^{\mathrm{F}}(\mathrm{t}+1) \equiv \mathrm{n}(\mathrm{t}) C \mathrm{n}(\mathrm{t})^{\mathrm{c}-1}=C \mathrm{n}(\mathrm{t})^{\mathrm{c}}, \quad 0<\mathrm{c}<1 .
\end{aligned}
$$

The choice of sector in which to work is once-and-for-all. Those choosing to work in the farm sector supply their labor in both periods of life. In order to capture "time to grow," it is that

assumed the $C>B \geq 0$ and $\mathrm{c} \geq \mathrm{b}$. Thus, farmers earn more in the second period of their lives than they do in their first period. Service producers supply labor only in the first periods of their lives. These assumptions are made partly for tractability. But since we assume no storage, our assumptions are made also to assure that in equilibrium farmers borrow and service providers lend.

We assume all private debt is in the form of one-period discount bonds, $\mathrm{B}^{\mathrm{P}}$. We take these to be nominal (nonindexed) bonds denominated in the currency of the economy where the issuer resides.

Farmers are distinguished by two characteristics in our model. One is that they are borrowers. The other is that only their good is world-traded. While services and food can be purchased and sold within an economy, only food can be traded between economies.

In addition to a private sector, both economies have a public sector. The public sector has a fiscal authority that consumes some amounts of its economy's services and food and levies lumpsum real taxes, quoted in food units, on young service providers and young farmers. We assume that its total consumption always matches or exceeds its total lump-sum tax revenue. (This permanent deficit assumption implies that, in steady states with positive real interest rates, inflation 
must be positive to generate the seignorage needed to finance government deficits.) An economy's budget policy is defined by the fiscal authority's real consumption of services and food, $\mathrm{g}^{\mathrm{s}} \geq 0$ and

$\mathrm{g}^{\mathrm{F}} \geq 0$, respectively; by its lump-sum taxes on service providers and farmers in their first period of life, $\tau$; and by its issue of one-period discount bonds, $\mathrm{B}^{\mathrm{G}}$, to finance the deficit.

Each public sector also has a monetary authority that engages in open-market operations and imposes a reserve requirement. Open-market operations are conducted by exchanging fiat money $\mathrm{H}$, for government bonds, and the reserve requirement is specified by a fraction of nominal savings which must be held in the form of money. An economy's monetary policy is defined by the ratio of the market value of government bonds to money, $\beta$, and by the reserve requirement, $\lambda$. Government bonds are traded in a world capital market, but in equilibrium an economy's money is held only by domestic lenders to satisfy reserve requirements.

\section{B. Market Equilibrium}

A market equilibrium is defined as an allocation of goods and sequences of prices such that at each date the allocation solves individual optimization problems given the prices, the quantities and prices are consistent with the two governments' budget constraints, and markets clear. And since individuals are able to choose in which sector to work, the expected utility from working in either sector must be equal in equilibrium.

There are six markets in the model: two world markets in food and bonds and four domestic markets in economy-specific services and money. By Walras's Law we eliminate separate consideration of the world bond market. In the remaining markets five price sequences are determined: the world real interest rate $(\rho)$, the relative price of services to food in each economy $\left(\mathrm{Q}\right.$ and $\left.\mathrm{Q}^{*}\right)$, and the rate of change of food prices in each economy $\left(\pi^{\mathrm{F}}\right.$ and $\left.\pi^{\mathrm{F}}\right)$. All other prices and quantities can be determined using these five price sequences. 
In addition to the six markets discussed in the previous paragraph, labor allocations also must be in equilibrium. Market-clearing sequences for $\rho, \mathrm{Q}, \mathrm{Q}^{*}, \pi^{\mathrm{F}}$, and $\pi^{\mathrm{F} *}$ can be determined for any labor market allocations. Thus, in equilibrium, the labor allocations across sectors must imply the five price sequences determined by market-clearing as well as expected utilities which are equal across sectors.

We next describe individual optimization problems, government budget constraints, and market-clearing conditions. We conclude this subsection with a description of an equilibrium.

\section{Individual Optimization Problems}

We describe the optimization problems of the old at date 1 (generation 0 ) and of the young at all dates (generation $t>0$ ). We only consider the home economy, since the individuals solve parallel problems in the foreign economy. Individuals take prices as given and have perfect foresight with respect to prices in their second period of life.

The old at $\mathrm{t}=1$ maximize

$$
\theta \log c_{0}^{s}(1)+(1-\theta) \log c_{0}^{\mathrm{f}}(1)
$$

subject to

$$
Q(1) c_{0}^{S}(1)+c_{0}^{F}(1)=A_{0}
$$

where

$$
A_{0} \equiv\left\{\begin{array}{ll}
{\left[\frac{1}{1-n(0)}\right]\left[\frac{H(0)+B^{G}(0)}{p^{F}(1)}+\frac{B^{p}(0)}{p^{F}(1)}\right]} & \text { for service providers } \\
X_{0}^{F}(1)-\frac{1}{n(0)} \frac{B^{P}(0)}{p^{F}(1)} & \text { for farmers }
\end{array}\right\}
$$

and where $Q(1) \equiv\left[p^{s}(1) / p^{F}(1)\right]$ is the relative price of services to food at date 1 . The real wealth of old service providers consists of the outside debt (money and bonds) of their government and the 
private debt of their economy's farmers-both deflated by the level of food prices. The real wealth of old farmers consists of their food production in the second period of their lives less the real value of debt they have outstanding. Note that for both types of old agents at $t=1$, the real value of $A_{0}$ depends on $\mathrm{p}^{\mathrm{F}}(1)$, an endogenous variable subject to the effects of policy changes in period 1 .

The optimization problem generates the usual Cobb-Douglas utility demand functions:

$$
\hat{\mathrm{c}}_{0}^{\mathrm{s}}(1)=\theta \mathrm{A}_{0} / \mathrm{Q}(1)
$$

and

$$
\hat{\mathrm{c}}_{0}^{\mathrm{F}}(1)=(1-\theta) \mathrm{A}_{0}
$$

where $A_{0}$ takes on the value specified above for old service providers and farmers, respectively. Agents born at dates $t \geq 1$ maximize

$$
\theta \log c_{t}^{s}(t)+(1-\theta) \log c_{t}^{F}(t)+\delta\left[\theta \log c_{t}^{s}(t+1)+(1-\theta) \log c_{t}^{F}(t+1)\right]
$$

subject to

$$
\mathrm{W}(\mathrm{t})=\mathrm{Q}(\mathrm{t}) \mathrm{c}_{\mathrm{t}}^{\mathrm{s}}(\mathrm{t})+\mathrm{c}_{\mathrm{t}}^{\mathrm{F}}(\mathrm{t})+\left[\mathrm{Q}(\mathrm{t}+1) \mathrm{c}_{\mathrm{t}}^{\mathrm{s}}(\mathrm{t}+1)+\mathrm{c}_{\mathrm{t}}^{\mathrm{F}}(\mathrm{t}+1)\right](1+\mathrm{i}(\mathrm{t}))
$$

where

$$
\begin{aligned}
& \mathrm{W}(\mathrm{t}) \equiv \begin{cases}\mathrm{Q}(\mathrm{t}) \mathrm{X}_{\mathrm{t}}^{\mathrm{S}}(\mathrm{t})-\tau(\mathrm{t}) & \text { for service providers } \\
\mathrm{X}_{\mathrm{t}}^{\mathrm{F}}(\mathrm{t})+\frac{\mathrm{X}_{\mathrm{t}}^{\mathrm{F}}(\mathrm{t}+1)}{1+\rho(\mathrm{t})}-\tau(\mathrm{t}) & \text { for farmers }\end{cases} \\
& 1+\mathrm{i}(\mathrm{t}) \equiv \begin{cases}1+\rho_{\mathrm{s}}(\mathrm{t}) & \text { for service providers } \\
1+\rho(\mathrm{t}) & \text { for farmers }\end{cases} \\
& \mathrm{r}(\mathrm{t}) \equiv \text { the nominal interest rate on one-period bonds issued at } \mathrm{t}
\end{aligned}
$$

and 


$$
\rho_{s}(t) \equiv[1+(1-\lambda(t)) r(t)] /\left[1+\pi^{F}(t)\right]-1, \text { the real rate of return on savings at } t
$$

Note that taxes are levied only on the young generation. Also note that the return to lenders (service providers) doesn't depend just on the real rate of return on bonds. Because lenders are legally required to hold a fraction of their assets as domestic currency, their net nominal rate of return is not $r$, the net nominal rate on bonds, but rather $(1-\lambda) r$, where $\lambda$ is the fraction of their assets that savers must hold in the form of money (suppressing dependence on $t$ ). It follows that the real rates earned by savers and paid by borrowers are related by $1+\rho_{s}=\lambda /(1+\pi)+(1-\lambda)(1+\rho)$. Only when $\lambda=0$ are the two rates the same.

The optimization problem again generates typical Cobb-Douglas utility demand functions:

$$
\begin{aligned}
& \hat{\mathrm{c}}_{\mathrm{t}}^{\mathrm{s}}(\mathrm{t})=\left[\frac{\theta}{1+\delta}\right] \mathrm{W}(\mathrm{t}) / \mathrm{Q}(\mathrm{t}) \\
& \hat{\mathrm{c}}_{\mathrm{t}}^{\mathrm{f}}(\mathrm{t})=\left[\frac{1-\theta}{1+\delta}\right] \mathrm{W}(\mathrm{t}) \\
& \hat{\mathrm{c}}_{\mathrm{t}}^{\mathrm{s}}(\mathrm{t}+1)=\left[\frac{\theta \delta}{1+\delta}\right]\left[\frac{\mathrm{W}(\mathrm{t})(1+\mathrm{i}(\mathrm{t}))}{\mathrm{Q}(\mathrm{t}+1)}\right]
\end{aligned}
$$

and

$$
\hat{\mathrm{c}}_{\mathrm{t}}^{\mathrm{F}}(\mathrm{t}+1)=\left[\frac{(1-\theta) \delta}{1+\delta}\right][\mathrm{W}(\mathrm{t})(1+\mathrm{i}(\mathrm{t}))]
$$

\section{Government Budget Constraint}

The government at date $t$ pays for current expenditures and the retirement of last period's bonds and money by issuing new bonds and money and by levying lump-sum taxes:

$$
p^{s}(t) g^{S}(t)+p^{F}(t) g^{F}(t)+B^{G}(t-1)+H(t-1)=P^{B}(t) B^{G}(t)+H(t)+p^{F}(t) \tau(t)
$$

where

$P^{B}(t)$ is the nominal price of government bonds at date $t$,

$P^{B}(t)=1 /(1+r(t))$ 
$\mathrm{B}^{\mathrm{G}}(\cdot)$ is the total nominal face value of government bonds,

$\mathrm{H}(\cdot)$ is the total quantity of money,

and

$\tau(t)$ is total lump-sum taxes in food units at date $t$.

Let the real value of bonds and money in terms of food at date $t$ be defined, respectively, by

$$
b^{G}(t) \equiv \frac{p^{B}(t) B^{G}(t)}{p^{F}(t)}
$$

and

$$
h(t) \equiv \frac{H(t)}{p^{F}(t)}
$$

In addition, let $\beta(\mathrm{t}) \equiv \mathrm{P}^{\mathrm{B}}(\mathrm{t}) \mathrm{B}^{\mathrm{G}}(\mathrm{t}) / \mathrm{H}(\mathrm{t})$.

Then the government budget constraint can be written

$$
\begin{aligned}
\mathrm{Q}(\mathrm{t}) \mathrm{g}^{\mathrm{S}}(\mathrm{t}) & +\mathrm{g}^{\mathrm{F}}(\mathrm{t})-\tau(\mathrm{t}) \\
= & {[1+\beta(\mathrm{t})] \mathrm{h}(\mathrm{t})-\left[\frac{1}{1+\pi^{\mathrm{F}}(\mathrm{t}-1)}+(1+\rho(\mathrm{t}-1)) \beta(\mathrm{t}-1)\right] \mathrm{h}(\mathrm{t}-1) . }
\end{aligned}
$$

\section{Market-Clearing Conditions}

We first define selected price variables and then express relationships among them which must hold in equilibrium. The aggregate price level in a particular economy is defined as

$$
P(t) \equiv p^{s}(t)^{\theta} p^{F}(t)^{(1-\theta)}
$$

which is a measure of the minimal cost of one unit of utility.

The nominal exchange rate, e, defines how many units of the foreign economy's currency are exchanged for one unit of the home economy's currency. By the Law of One Price applied to the traded good, $e(t) p^{F}(t)=p^{F^{*}}(t)$, or $e(t)=p^{F^{*}}(t) / p^{F}(t)$. The real exchange rate, then, is defined as the nominal exchange rate divided by the ratio of the price levels, or 


$$
\overline{\mathrm{e}}(\mathrm{t}) \equiv \mathrm{e}(\mathrm{t}) /\left[\mathrm{P}^{*}(\mathrm{t}) / \mathrm{P}(\mathrm{t})\right]=\left[\mathrm{Q}(\mathrm{t}) / \mathrm{Q}^{*}(\mathrm{t})\right]^{\theta}
$$

Since private and government bonds within an economy are perfect substitutes, their nominal (as well as real) rates of return must be the same in equilibrium-a fact we already used in stating the optimization problems. Moreover, because domestic and foreign bonds are perfect substitutes, it follows that the real interest rates in equilibrium must be the same in each economy:

$$
\frac{1+\mathrm{r}(\mathrm{t})}{1+\pi^{\mathrm{F}}(\mathrm{t})} \equiv 1+\rho(\mathrm{t})=1+\rho^{*}(\mathrm{t}) \equiv \frac{1+\mathrm{r}^{*}(\mathrm{t})}{1+\pi^{\mathrm{F}^{*}}(\mathrm{t})}
$$

We'll refer to this single real rate as $\rho(\mathrm{t})$.

\section{Equilibrium and Solution}

All equilibrium quantities and prices can be derived from the equilibrium values of the seven sequences: $\rho, \mathrm{Q}, \mathrm{Q}^{*}, \pi^{\mathrm{F}}, \pi^{\mathrm{F}}, \mathrm{n}$, and $\mathrm{n}^{*}$. For given sequences $\mathrm{n}$ and $\mathrm{n}^{*}$ the model is identical to the endowment economy of Miller and Todd (1995) when the following substitutions are made:

$$
\begin{aligned}
& \overline{\mathrm{w}}_{\mathrm{t}}^{\mathrm{s}}(\mathrm{t}) \equiv A(1-\mathrm{n}(\mathrm{t}))^{\mathrm{a}}-\frac{(1-\mathrm{n}(\mathrm{t})) \tau(\mathrm{t})}{\mathrm{Q}(\mathrm{t})} \\
& \overline{\mathrm{w}}_{2}^{\mathrm{F}}(\mathrm{t}) \equiv B \mathrm{n}(\mathrm{t})^{\mathrm{b}}-\mathrm{n}(\mathrm{t}) \tau(\mathrm{t}) \\
& \overline{\mathrm{w}}_{\mathrm{t}-1}^{\mathrm{F}}(\mathrm{t}) \equiv \mathrm{Cn}(\mathrm{t}-1)^{\mathrm{c}} \\
& \overline{\mathrm{g}}^{\mathrm{S}}(\mathrm{t}) \equiv \mathrm{g}^{\mathrm{s}}(\mathrm{t})-\frac{(1-\mathrm{n}(\mathrm{t})) \tau(\mathrm{t})}{\mathrm{Q}(\mathrm{t})} \\
& \overline{\mathrm{g}}^{\mathrm{F}}(\mathrm{t}) \equiv \mathrm{g}^{\mathrm{F}}(\mathrm{t})-\mathrm{n}(\mathrm{t}) \tau(\mathrm{t})
\end{aligned}
$$

and similarly for the foreign country. That is, the equilibrium conditions in Miller and Todd (1995) assumed an endowment economy with zero lump-sum taxes. Substituting these variables with overbars for those in Miller and Todd (1995) without overbars yields equilibrium conditions for the present production economy with lump-sum taxes. 
Equilibrium sequences of the price variables can be derived by equating demand and supply in the goods and money markets. Market demands and supplies are found by adding up the individual demands and supplies of the agents and governments that participate in the markets. The dynamic equilibrium conditions for $\mathrm{t} \geq 2$ are

Home Services Market

$$
\begin{aligned}
\overline{\mathrm{w}}_{\mathrm{t}}^{\mathrm{S}}(\mathrm{t})= & {\left[\frac{\theta \delta}{1+\delta}\right]\left[\frac{1}{\mathrm{Q}(\mathrm{t})}\right]\left[(1-\lambda)(1+\rho(\mathrm{t}-1))+\frac{\lambda}{1+\pi^{\mathrm{F}}(\mathrm{t}-1)}\right] \mathrm{Q}(\mathrm{t}-1) \overline{\mathrm{w}}_{\mathrm{t}-1}^{\mathrm{S}}(\mathrm{t}-1) } \\
& +\left[\frac{\theta}{1+\delta}\right] \overline{\mathrm{w}}_{\mathrm{t}}^{\mathrm{S}}(\mathrm{t})+\left[\frac{\theta \delta}{1+\delta}\right]\left[\frac{1}{\mathrm{Q}(\mathrm{t})}\right]\left[(1+\rho(\mathrm{t}-1)) \overline{\mathrm{w}}_{\mathrm{t}-1}^{\mathrm{F}}(\mathrm{t}-1)+\overline{\mathrm{w}}_{\mathrm{t}-1}^{\mathrm{F}}(\mathrm{t})\right] \\
& +\left[\frac{\theta}{1+\delta}\right]\left[\frac{1}{\mathrm{Q}(\mathrm{t})}\right]\left[\overline{\mathrm{w}}_{\mathrm{t}}^{\mathrm{F}}(\mathrm{t})+\frac{\overline{\mathrm{w}}_{\mathrm{t}}^{\mathrm{F}}(\mathrm{t}+1)}{1+\rho(\mathrm{t})}\right]+\overline{\mathrm{g}}^{\mathrm{S}}(\mathrm{t}) .
\end{aligned}
$$

Foreign Services Market

(Same with * variables.)

World Food Market

$$
\begin{aligned}
\overline{\mathrm{w}}_{\mathrm{t}-1}^{\mathrm{F}}(\mathrm{t}) & +\overline{\mathrm{w}}_{\mathrm{t}}^{\mathrm{F}}(\mathrm{t})+[* \text { same }] \\
= & {\left[\frac{(1-\theta) \delta}{1+\delta}\right]\left[(1-\lambda)(1+\rho(\mathrm{t}-1))+\frac{\lambda}{1+\pi^{\mathrm{F}}(\mathrm{t}-1)}\right] \mathrm{Q}(\mathrm{t}-1) \overline{\mathrm{w}}_{\mathrm{t}-1}^{\mathrm{S}}(\mathrm{t}-1) } \\
& +\left[\frac{(1-\theta) \delta}{1+\delta}\right][1+\rho(\mathrm{t}-1)]\left[\overline{\mathrm{w}}_{\mathrm{t}-1}^{\mathrm{F}}(\mathrm{t}-1)+\frac{\overline{\mathrm{w}}_{\mathrm{t}-1}^{\mathrm{F}}(\mathrm{t})}{1+\rho(\mathrm{t}-1)}\right] \\
& +\left[\frac{1-\theta}{1+\delta}\right] \mathrm{Q}(\mathrm{t}) \overline{\mathrm{w}}_{\mathrm{t}}^{\mathrm{S}}(\mathrm{t})+\left[\frac{1-\theta}{1+\delta}\right]\left[\overline{\mathrm{w}}_{\mathrm{t}}^{\mathrm{F}}(\mathrm{t})+\frac{\overline{\mathrm{w}}_{\mathrm{t}}^{\mathrm{F}}(\mathrm{t}+1)}{1+\rho(\mathrm{t})}\right]+\overline{\mathrm{g}}^{\mathrm{F}}(\mathrm{t}) \\
& +\left[{ }^{*} \text { same }\right] .
\end{aligned}
$$


Home Money Market

$$
\begin{aligned}
\mathrm{Q}(\mathrm{t}) \overline{\mathrm{g}}^{\mathrm{S}}(\mathrm{t})+\overline{\mathrm{g}}^{\mathrm{F}}(\mathrm{t}) & =\left[\frac{\lambda \delta}{1+\delta}\right] \times \\
& \left\{(1+\beta(\mathrm{t})) \mathrm{Q}(\mathrm{t}) \overline{\mathrm{w}}_{\mathrm{t}}^{\mathrm{S}}(\mathrm{t})-\left[\frac{1}{1+\pi^{\mathrm{F}}(\mathrm{t}-1)}+(1+\rho(\mathrm{t}-1)) \beta(\mathrm{t}-1)\right] \mathrm{Q}(\mathrm{t}-1) \overline{\mathrm{w}}_{\mathrm{t}-1}^{\mathrm{S}}(\mathrm{t}-1)\right\} .
\end{aligned}
$$

Foreign Money Market

(Same with * variables.)

Given the equilibrium price sequences, the equilibrium labor market allocation sequences can be found as those values which equate utility derived from working in either sector by a young individual. This is not simply a present value of income calculation, since individuals in the two sectors face different rates of return. The dynamic equilibrium conditions for $\mathrm{n}$ and $\mathrm{n}^{*}$ are

Equality of Employment Payoffs, Home

$$
\begin{aligned}
& (1+\delta) \ln \left\{\frac{\mathrm{n}(\mathrm{t})(1+\rho(\mathrm{t})) \mathrm{Q}(\mathrm{t}) \overline{\mathrm{w}}_{\mathrm{t}}^{\mathrm{S}}(\mathrm{t})}{(1-\mathrm{n}(\mathrm{t}))\left[(1+\rho(\mathrm{t})) \overline{\mathrm{w}}_{\mathrm{t}}^{\mathrm{F}}(\mathrm{t})+\overline{\mathrm{w}}_{\mathrm{t}}^{\mathrm{F}}(\mathrm{t}+1)\right]}\right\} \\
& +\delta \ln \left\{(1-\lambda)+\frac{\lambda}{(1+\rho(\mathrm{t}))\left(1+\pi^{\mathrm{F}}(\mathrm{t})\right)}\right\}=0 .
\end{aligned}
$$

Equality of Employment Payoffs, Foreign

(Same with * variables.)

An equilibrium for the entire system is a solution to the seven equations in seven unknowns. It can be thought of as the intersection of a set of price sequences that satisfy equations (1)-(5) for given labor allocation sequences and a pair of labor allocation sequences which satisfy equations (6)-(7) for given price sequences. 
Equilibrium conditions for $t=1$ are slightly different than those for $t \geq 2$, because they depend on the outside debt held by the initial old. Their precise specification can be found in Miller and Todd (1992).

In order to describe our methodology, we write our seven-equation system (1)-(7) in the implicit function form:

$$
\begin{aligned}
& F^{3}\left(\rho(t), Q(t), Q^{*}(t), \pi^{F}(t-1), \pi^{F^{*}}(t-1) ; n(t), n^{*}(t) ; L(t), \beta^{*}(t), \gamma(t)\right)=0 \\
& F^{1}\left(\rho(t), Q(t), \pi^{F}(t-1) ; n(t) ; L(t), \gamma(t)\right)=0 \\
& F^{2}\left(\rho(t), Q^{*}(t), \pi^{F^{*}}(t-1) ; n^{*}(t) ; L(t), \beta^{*}(t), \gamma(t)\right)=0 \\
& F^{4}\left(Q(t), \pi^{F}(t-1) ; n(t) ; L(t) ; \gamma(t)\right)=0 \\
& F^{5}\left(Q^{*}(t), \pi^{F^{*}}(t-1) ; n^{*}(t) ; L(t) ; \beta^{*}(t), \gamma(t)\right)=0 \\
& F^{6}\left(n(t) ; \rho(t), Q(t), \pi^{F}(t) ; \gamma(t)\right)=0 \\
& F^{7}\left(n^{*}(t) ; \rho(t), Q^{*}(t), \pi^{F *}(t) ; \gamma(t)\right)=0,
\end{aligned}
$$

where the number of each equation refers to the corresponding market-clearing condition in the text, $\mathrm{L}$ includes lagged values of all seven variables preceding $\mathrm{L}$ in equation (3) and $\gamma$ includes all parameters other than $\beta^{*}$.

We first describe our steady-state solution methodology, and then describe our methodology for solving the model dynamically under floating exchange rates following a perturbation. Finally, we describe the differences in the system of equations moving from the floating to the fixed exchange rate regimes.

Our solution method and comparative dynamics exercises make heavy use of steady-state properties of the model. Initially, we work with the steady-state version of the model and assume parameters that imply a unique symmetric steady state with a positive real interest rate. ${ }^{5}$ In order to solve for a steady state we drop the time-dependence of variables in $\mathrm{F}^{1}-\mathrm{F}^{7}$. We note that given values of $n$ and $n^{*}$, (1)-(5) form a system of five equations in five unknowns, which can be solved 
as in Miller and Todd. We solve the whole system (1)-(7) iteratively. We begin with initial values of $n_{0}=n_{0}^{*}=1 / 2$, solve (1)-(5) for $\chi_{0} \equiv\left\langle\rho_{0}, Q_{0}, Q_{0}^{*}, \pi_{0}^{F}, \pi_{0}^{F^{*}}\right\rangle$. The ordering of the first five equations is the one we follow in our solution algorithm. That is, given initial values we solve (3) for $\rho$, then given that value of $\rho$ solve (1) and (2) for $\mathrm{Q}$ and $\mathrm{Q}^{*}$, respectively, and given those values of $\rho, \mathrm{Q}$, and $Q^{*}$, solve (4) and (5) for $\pi^{F}$ and $\pi^{F^{*}}$, respectively. We then use (6) and (7) to solve for the n's as functions of $\chi_{0}$. For the next iteration we choose values of the $n^{\prime} s$ by $n_{1}=n_{0}+$ damp . $\left(n\left(\chi_{0}\right)-n_{0}\right)$ and similarly for $n^{*}$, where damp $=0.3$ was found to assure convergence. We continue these iterations until the system converges. The initial steady-state solution is the same whether the exchange rate system is floating or fixed.

We next go to the $t=1$ conditions and assume values of outside debt in each country that imply the economy is in the initial steady state. That is, when starting the economy up with these values of nominal outside debt, the $t=1$ and $t \geq 2$ sets of equations produce the associated steady state.

In order to do policy and other experiments we adopt the following timing assumptions: First, we assume all policy and other parameter shocks are once-and-for-all and occur at $\mathrm{t}=1$. Second, we assume that the young at $t=1$ come on the scene and make their career choices, and then the policy or other parameter shocks occur. In other words, we assume that all policy or other parameter changes are unanticipated by the initial old and initial young. Thus, $n(1)$ and $n^{*}(1)$ remain at their initial steady-state values, while $n(t)$ and $n^{*}(t)$ adjust for $t \geq 2$. More specifically, for $t=$ 1 we solve just (1)-(5) with $n(1)$ and $n^{*}(1)$ at their initial steady-state values, and then from $t=2$ onwards we solve (1)-(7).

All effects from parameter perturbations are measured as deviations over time between the initial steady state and the perturbed dynamic path. In our experiments we find that the perturbed 
path converges to a new steady-state path by $t \leq 8$. Because of this, we are able to quickly solve forward for the perturbed dynamic paths.

At first glance solving the dynamic system seems daunting: at each date $t$ there are seven equations and nine unknowns since $\pi^{\mathrm{F}}(\mathrm{t}-1)$ and $\pi^{\mathrm{F}^{*}}(\mathrm{t}-1)$ enter the first five equations and $\pi^{\mathrm{F}}(\mathrm{t})$ and $\pi^{F^{*}}(t)$ enter the next two equations. ${ }^{6}$ However, since a perturbation quite rapidly leads to a new steady state, we observe that $\pi^{\mathrm{F}}(7) \approx \pi^{\mathrm{F}}(8)$ and $\pi^{\mathrm{F}^{*}}(7) \approx \pi^{\mathrm{F}^{*}}(8)$. Thus, we are led again to a simple iterative technique. We start with initial paths of $n_{0}(t), n_{0}^{*}(t), t=1, \ldots, 8$ equal to their steady-state values. With these paths, perturbations lead to nonconstant paths of $\chi_{0}(t) \equiv\left\langle\rho_{0}(t), Q_{0}(t)\right.$, $\left.\mathrm{Q}_{0}^{*}(\mathrm{t}), \pi_{0}^{\mathrm{F}}(\mathrm{t}), \pi_{0}^{\mathrm{F}^{*}}(\mathrm{t})\right\rangle \mathrm{t}=1, \ldots, 8$, assuming $\pi_{0}^{\mathrm{F}}(7)=\pi_{0}^{\mathrm{F}}(8)$ and $\pi_{0}^{\mathrm{F}^{*}}(7)=\pi_{0}^{\mathrm{F}^{*}}(8)$. We solve for the paths of $\chi_{0}(t)$ using equations (1)-(5) and the method of Miller and Todd. Using the path for $\chi_{0}(t)$, we use equations (6) and (7) to solve for paths of $n\left(t, \chi_{0}(t)\right)$ and $n^{*}\left(t, \chi_{0}(t)\right)$, and for the next iteration at each $t$, we set $n_{1}(t)=n_{0}(t)+$ damp $\cdot\left(n\left(t, \chi_{0}(t)\right)-n_{0}(t)\right)$ and similarly for $n_{1}^{*}(t)$. We then iterate until all seven variables, $\chi, n, n^{*}$, at each date converge. That is, $\left\langle\chi_{k}(t), n_{k}(t), n_{k}^{*}(t)\right\rangle \approx\left\langle\chi_{k-1}(t)\right.$, $\left.n_{k-1}(t), n_{k-1}^{*}(t)\right\rangle$ at each date $t$, where $k$ is the last iteration.

We solve our system in an analogous way under fixed exchange rates. The initial steady-state solution is no different. For the dynamic system we substitute $\pi^{\mathrm{F}}$ for $\pi^{\mathrm{F} *}$ wherever the latter appears in (1)-(7). Then for given paths of $n(t)$ and $n^{*}(t)$, we use equations (1)-(5) to solve for paths of $\rho(t)$, $Q(t), Q^{*}(t), \pi^{F}(t)$, and $\beta^{*}(t)$. Thus, for fixed exchange rates, at each date the price of food in the foreign country is equated to that in the home country $\left(\mathrm{p}^{\mathrm{F}^{*}}(\mathrm{t})=\mathrm{e} \cdot \mathrm{p}^{\mathrm{F}}(\mathrm{t})\right.$, and initial symmetry implies $\mathrm{e}=1$ ) and the foreign monetary policy indicator $\beta^{*}$ is endogenous and possibly varying over time. 


\section{Analysis}

In this section we compare the differences under fixed rate and floating rate regimes of economic responses to shocks. The responses include movements in aggregate price and quantity variables as well as in measures of welfare for various groups of agents. All shocks are considered to be unanticipated one-time changes to parameters at $t=1$ which are maintained for all time. Since there are so many variables and parameters, we limit our analysis to three experiments and describe the outcomes for a limited set of variables.

The three experiments are intended to illustrate some basic principles:

- Experiment 1 shows that for some shocks fixed exchange rates can be maintained by changes only to foreign monetary policy. Those changes need not require a change in foreign budget policy. For shocks such as these the differences in responses under fixed and floating exchange rates is wholly attributable to differences in the path of foreign monetary policy.

- Experiment 2 shows that for other shocks, changes in foreign monetary policy alone, which are required to keep the exchange rate fixed, result in an inconsistency between foreign monetary policy and foreign budget policy. We show how foreign budget policy then can be changed to make the two policies consistent. For shocks such as these differences in responses under fixed and floating exchange rates is attributable to differences in paths of both foreign monetary policy and foreign budget policy.

- Experiment 3 shows that a foreign country's agents may prefer a floating exchange rate regime at some times but a fixed rate regime at other times. Their choice is shown to depend on initial conditions. Somewhat counterintuitively, their choice is different under voting and under a social planner. 
Experiment 1. An Increase in $\beta$ : A Tightening in the Home Country's Monetary Policy

In this experiment $\beta$, the ratio of the market value of government bonds to base money in the home country, is increased once-and-for-all by 1 percent at date $t=1$. In the floating exchange rate regime all other parameters are kept at their initial steady-state values. In the fixed exchange rate version $\beta^{*}$ is allowed to vary beginning at date $t=1$ in order to keep the nominal exchange rate at its initial steady-state value for all time.

Under floating exchange rates the experiment is essentially the same as in Miller and Todd (1995) for their large country case (see pp. 142-44 in Miller and Todd 1995). However, there are two differences. First, the initial parameter sets are different. In Miller and Todd (1995) the parameters were chosen from a fairly large sample to give the median responses to a change in $\beta$. Here, the initial parameter values are chosen to yield values of variables with real-world analogues like interest rates, inflation, government deficits, and base money that fall into recent historical ranges. This difference has little effect qualitatively on the results. Second, in Miller and Todd (1995) labor allocations can be considered fixed for all time. Here, beginning at $t=2$ the young can choose in which sector to work. So, beginning at that time, the distribution of goods supplied in each country is allowed to change. The difference in results from this alteration in assumptions is fairly major in both positive and normative respects. With respect to positive effects, allowing $n(t)$ and $n(t)^{*}$ to vary as opposed to holding them constant results in

1. A more rapid transition to a new steady state,

2. A large part of that transition occurring at $t=2$ when young agents first are free to choose where to work, and

3. A stronger tendency for the two economies to converge. 
With respect to normative effects, the utilities of agents in both sectors of a given economy must coincide beginning at $\mathrm{t}=2$ as opposed to potentially differing for all time.

The third positive implication is not intuitive. One might have thought that labor mobility within an economy would cause differences between the sectors in that economy to shrink. But one also might have thought that since there is no labor mobility between the two economies, differences between the economies can persist. But those differences also shrink for this experiment. The reasoning is as follows. With no mobility between sectors inflation rates can differ permanently in the two economies, and this difference creates permanent differences in many other aggregate variables in the two economies such as the relative returns to borrowers and lenders, the relative price of traded and nontraded goods, the real exchange rate, and the current account balance. However, with labor mobility the difference in returns to borrowers and lenders must return to close to where it was initially. Since there is a world capital market, the returns to borrowers in the two countries at any date must be the same. Thus, the reversion to initial values of relative returns in each country coupled with a common return to borrowers in the two countries implies that the returns to savers in the two countries must converge. With the return to savers in each economy being a weighted-average of the common real interest rate and that economy's inflation rate, the two inflation rates must converge. Thus, labor market mobility within a country and perfect capital mobility between countries causes the behavior of the two economies to be similar following a change in only one country's monetary policy.

Under fixed exchange rates the value of $\beta^{*}$ is also increased once-and-for-all by 1 percent at date $t=1$. The reason this results in an unchanged nominal exchange rate is easy to see. Initially, the two economies are assumed to be identical. When $\beta^{*}$ is changed identically with $\beta$, the two economies remain identical, but with a new value of $\beta=\beta^{*}$. Thus, the sequences of all price variables are the same across countries, and in particular $e(t) \equiv \mathrm{p}^{F^{*}}(\mathrm{t}) / \mathrm{p}^{\mathrm{F}}(\mathrm{t})=1$ for all $\mathrm{t}$ both before 
and after the change in $\beta$ and $\beta^{*}$. In this case the experiment is no different than a tightening of monetary policy in a closed economy.

The dynamic outcomes of this experiment are compared under floating and fixed exchange rates in Figures 1a-1p. Figures $1 \mathrm{a}$ and $1 \mathrm{~b}$ show that $\beta$ is increased at date $t=1$ under both floating and fixed exchange rates, but $\beta^{*}$ is increased and by the same amount at date $t=1$ only under fixed exchange rates. The differences in outcomes under fixed and floating exchange rates for the same aggregative variables in Figures $1 c-11$ all result from the higher level of $\beta^{*}$ under fixed exchange rates.

The behavior of the sequences $\rho, \mathrm{Q}, \mathrm{Q}^{*}, \pi, \pi^{*}, \mathrm{n}$, and $\mathrm{n}^{*}$ as depicted in Figures $1 \mathrm{c}$ and $1 \mathrm{e}-1 \mathrm{j}$ are for the most part similar qualitatively under floating and fixed exchange rates. However, there are differences at date $t=1$ under the two regimes. These differences are due to the real wealth effects at $\mathrm{t}=1$. Under floating exchange rates, a higher $\beta$ acts like an open-market sale in the home country, decreasing its stock of base money and its price level $\mathrm{p}^{\mathrm{F}}(1)$ and thus increasing the real wealth of the initial old. This initially increases the total wealth of the home country relative to the foreign country. Higher wealth drives up the demand for goods in the home country, but home country agents can consume more of only the traded good, and so the home country initially runs a trade deficit. In order for home country agents to be satisfied with the same amount of nontraded goods, its price relative to the price of traded goods must initially rise. The opposite outcomes occur in the foreign country. The rise in the relative price of nontraded goods to traded goods in the home country and its fall in the foreign country imply that the real exchange rate initially rises.

Under fixed exchange rates the wealth effects of a change in $\beta$ and $\beta^{*}$ are identical in the two countries. There can be no trade imbalance and so the supplies of both traded and nontraded goods in each country must be unchanged after the policy changes. Given the nature of the preference functions, the relative prices also remain unchanged in each country. Thus, the trade balances and 
real exchange rates also remain unchanged. After $t=1$, there is some difference in the behavior of $\mathrm{n}$ and $\mathrm{n}^{*}$, and thus the home and foreign output distributions and $\mathrm{Q}$ and $\mathrm{Q}^{*}$ are different under the two regimes.

The normative outcomes under the two regimes in Figures $1 \mathrm{~m}-1 \mathrm{p}$ are easily explained. At date $t=1$, the main effect of a higher $\beta$ is a higher $\rho$ and this makes savers better off and borrowers worse off. A further rise in $\beta^{*}$ under fixed exchange rates raises $\rho$ even more, making savers even better off and borrowers even worse off. At date $t=2$ and beyond, workers' mobility causes the utilities of savers and borrowers to be the same.

Experiment 2. An Increase in $\lambda$ : Higher Reserve Requirements in the Home Country

In this experiment $\lambda$, the reserve requirement in the home country, is increased once-and-forall by 1 percent at date $t=1$. The shock in this experiment might be construed as a change in the home country's financial structure that increases its demand for money. Under floating exchange rates all other parameters are kept at their initial steady-state levels. Under fixed exchange rates, two cases are examined. In the first case, the foreign monetary authority attempts to maintain the nominal exchange rate at its initial steady-state value by setting $\beta^{*}$ period by period. We show that this is not a feasible policy, because it causes the value of the real interest rate to rise without limit. In the second case, the foreign monetary authority raises $\beta^{*}$ once-and-for-all at $t=1$ (by slightly less than it does at $t=1$ in the first case) and at the same time the foreign budget authority reduces its spending on services once-and-for-all by a little over 6.5 percent. We show that under these policies the economies make a transition to a new steady state with an unchanged nominal exchange rate. Thus, this experiment illustrates that under some unforeseen changes in economic conditions, a country may need to change its budget policy in addition to its monetary policy in order to maintain a fixed nominal exchange rate. 
The dynamic outcomes of this experiment are compared in Figures 2a-2h. The key to understanding the difference in outcomes is to focus on the first period. Under floating exchange rates, a rise in $\lambda$ causes at $t=1$ a rise in $\rho$ (Figure 2b) and a fall in the home country's price level (Figure 2e, and recall that $\pi^{\mathrm{F}}(0) \equiv \mathrm{p}^{\mathrm{F}}(1) / \mathrm{p}^{\mathrm{F}}(0)-1$ ). If the foreign country does not respond with a change in its monetary policy $\beta^{*}$, a new steady state is quickly approached with a higher real interest rate and a slightly higher inflation rate in each country. The higher real interest rate results because, with a higher $\lambda$, less savings are available to satisfy the demand for loans. Since both governments are debtors, the higher real interest rate implies a higher interest expense on the governments' debt and, hence, higher inflation rates. ${ }^{7}$

Now suppose the foreign country attempts to peg the nominal exchange rate at its initial steady-state value by changing $\beta^{*}$. In the first period it must raise $\beta^{*}$ to reduce its country's price level $\mathrm{p}^{\mathrm{F}}(1)^{*}$ to match that of the home country. The effects of a higher $\beta^{*}$ in this case can be seen by examining the effects of a higher $\beta$ under floating exchange rates in the previous experiment. In particular, it results in a higher real interest rate $\rho$ immediately and a relatively higher value of the price level $\mathrm{p}^{\mathrm{F}}(2)^{*}$ to $\mathrm{p}^{\mathrm{F}}(2)$ in the next period. Thus, in the next period, the foreign monetary authority has to raise $\beta^{*}$ again, and the process continues until the interest expense on the government's debt is too large to finance by inflation seignorage alone. ${ }^{8}$

However, if the foreign country tightens its budget policy (by reducing $\mathrm{g}^{\mathrm{s*}}$ ) at the same time that it tightens its monetary policy, the economies quickly move to a new steady state. A tighter budget policy reduces the need for seignorage sufficiently to offset the increased need caused by a higher real interest expense from the monetary tightening. 
Experiment 3. A Reversal in the Foreign Country's Preference for Fixed vs. Floating Exchange Rates

We do a simple experiment to demonstrate that under some initial conditions the foreign country would prefer a fixed exchange rate system, while under others it would prefer floating exchange rates. Under all conditions we assume that the home country tightens its monetary policy by raising $\beta$ by 1 percent. If the foreign country chooses a fixed exchange rate system, it pegs the nominal exchange rate by raising $\beta^{*}$ by 1 percent. If, instead, it chooses floating exchange rates, it keeps $\beta^{*}$ unchanged. The changes to initial conditions are equal changes to the scalar production parameters in each country's traded goods sector, $B$ and $B^{*}$.

The foreign country's choice for one regime against the other is decided in two ways. The first is voting, and the second is a social planner. We first describe the voters' choice and next the social planner's choice. We then discuss why even though each process implies an exchange rate choice reversal, the reversals are in opposing directions.

Under voting, we assume that all foreign agents alive at $\mathrm{t}=1$ cast ballots on whether they prefer keeping $\beta^{*}$ unchanged in light of a 1 percent increase in $\beta$ (floating) or raising $\beta^{*}$ by 1 percent also (fixed). The numbers of farmers and service providers in generations 0 and 1 are determined in the initial steady state and are unaffected by the $\beta^{*}$ choice. Individuals choose the regime which generates for them the highest utility. For the young agents at $t=1$, their votes are tabulated in Table 1, where ' denotes fixed exchange rates and no superscript indicates floating exchange rates.

Determining how the old vote is a little less direct. The problem is we only determine total consumption of the old: we do not determine the consumption of old farmers and old service producers separately. That is because we do not specify the amount of existing debt old farmers have with old service producers. However, we can determine qualitatively how their consumption, and hence utility, changes with a higher $\beta^{*}$. A higher $\beta^{*}$ affects the utilities of both old farmers and 
old service producers only through the channels of a higher $Q(1)^{*}$ and a lower $\mathrm{p}^{\mathrm{F}}(1)^{*}$. Since old farmers produce food and pay off debts, they are made worse off by both changes. Since old service producers are paid off in food, they too are made worse off by an increase in $Q(1)^{*}$. But they also hold the inside debt $\mathrm{B}^{\mathrm{P}}(0)^{*}$ and outside nominal debt $\mathrm{M}(0)^{*}+\mathrm{B}^{\mathrm{G}}(0)^{*}$ and benefit by a decrease in $p^{F}(1)^{*}$ which raises their real wealth. Since an increase in $\beta^{*}$ raises $Q(1)^{*}$ but decreases $p^{F}(1)^{*}$, the choice of old service producers would seem to be ambiguous. But we know that the consumption of food and services of farmers will be reduced by a higher $\beta^{*}: \mathrm{c}_{\mathrm{F}}^{\mathrm{F}}(0)^{* \prime}<\mathrm{c}_{\mathrm{F}}^{\mathrm{F}}(0)^{*}$ and $\mathrm{c}_{\mathrm{F}}^{\mathrm{S}}(0)^{* \prime}<$ $\mathrm{c}_{\mathrm{F}}^{\mathrm{S}}(0)^{*}$. Thus, if the total consumption of food and services by the old increases with an increase in $\beta^{*}$, the consumption and hence utility of old service producers must also increase with an increase in $\beta^{*}$. Hence, the votes of the current old are tabulated in Table 2.

For the second way of choosing an exchange rate regime we assume there is a social planner who weights the utilities of all own-country agents from current and all future generations. As long as the social planner does not discount the utility of future generations too heavily, this choice can be made based on steady-state utilities. Since the economy quickly moves to a new steady state following a policy change, and all agents' utilities are equalized beginning in the second period, the steady-state utility realized by all agents after the first few periods will dominate the social planner's weighting of utilities. Thus, the social planner will choose a fixed exchange rate regime if steadystate utility is higher under that regime than under floating rates.

In the Tables $3-5$ we illustrate that as $B=B^{*}$ is increased, voters move from favoring a fixed exchange rate system to favoring a floating exchange rate system. The social planner's choice also reverses, but in the opposite direction. Tables 3-5 indicate that as $B=B^{*}$ increases,

- The number of agents who go into farming increases,

- Voters move from a preference for fixed exchange rates to a preference for floating exchange rates, and 
- A social planner moves from a preference for floating exchange rates to a preference for fixed exchange rates.

These results are explained as follows.

As $B=B^{*}$ increases, the productivity of farming in an agent's first period increases. This change causes agents to switch from service production to farming for two reasons: the relative productivity of farming to services increases, and with more first-period resources, farmers need to borrow less and thereby face a lower real interest rate.

The voters' and social planner's opposing preferences for regimes is due to two causes. First, voters have no choice about which sector in which to work (their $\mathrm{n}^{*}$ is independent of regime), while in the time horizon relevant to the social planner, agents can make that choice. Second, because generations are not completely linked by bequests, current generations overly discount the welfare of future generations. (In our model we take the extreme position that there are no bequests, and so future generations' welfare receives zero weight.)

The voters' preference for exchange rate regime is straightforward. In our model an easier monetary policy hurts savers (service producers) and benefits borrowers (farmers). As $B=B^{*}$ increases, the percentage of voters who are farmers increases. Thus, if the country initially favors fixed exchange rates, a rise in $B=B^{*}$ will eventually lead to a sufficient increase in the number of farmers to favor the easier monetary policy implied by floating exchange rates.

In contrast, the social planner is concerned with the welfare of future generations, something the voters ignore. Future generations do not care which sector initially benefits from any shock. They can choose where to work. They just care as a bloc about the efficiency of the economy. For instance, future generations do not care that under current deficit policies borrowers are hurt and lenders are helped, because future generations can choose to be either borrowers or lenders. What 
they care about is that the higher is current deficit spending, the lower will be the total amount of goods available for consumption when they are alive.

In order to understand how efficiency and choice of exchange rate system are linked, let us consider the global economy as a whole and associate an easy monetary policy with floating exchange rates and a tight monetary policy with fixed exchange rates. Now suppose there is an increase in farm productivity, and ask when a tighter monetary policy can be expected to lead to a more efficient outcome. The higher productivity represents an increase in wealth, and with perfect labor mobility this wealth must be shared equally by all agents in a generation. The wealth-sharing can be achieved through two channels:

- By increasing $\mathrm{n}$, so that farm productivity falls and service productivity rises, and

- By increasing $\rho$, so that farmers' (borrowers') terms of trade with service producers (lenders) worsen.

As $B=B^{*}$ increases, it becomes more efficient to handle more of the wealth transfer through the financial channel. Under an easy monetary policy, the productivity channel is used relatively more. That is, as $B=B^{*}$ increases, $\mathrm{n}^{*}$ increases more when $\beta^{*}$ is unchanged than when it is raised. However, transferring wealth through changes in $\mathrm{n}^{*}$ becomes more costly as $\mathrm{n}^{*}$ increases because of decreasing marginal productivity in farming. Thus, when $B=B^{*}$ gets high enough, transferring wealth through increases in $\mathrm{n}^{*}$ becomes more costly than transferring it through a higher $\rho$. In our model that means as initial conditions cause a rise in the number of farmers, a social planner will tend to favor fixed over floating exchange rates.

Our results depend very much on there being real frictions to generate the demands for money. For example, we find that a social planner at times may prefer fixed exchange rates, because at times a change in monetary policy in the face of an external shock leads to a more 
efficient outcome than does no change. Agents cannot respond optimally because the reserve requirement friction causes a distortion in their labor allocation decisions.

This distortion clearly results in a welfare loss. Although the utilities of farmers and service producers are equated in equilibrium, their consumption bundles are different. Thus, there conceivably exist trades which would allow individuals to realize a convex combination of the two bundles, putting them on a higher indifference curve. The distance between the higher indifference curve and the highest indifference curve attainable in the model is a measure of the welfare loss of the reserve requirements. The model prohibits the trades which would bring agents to the higher indifference curve. Those trades consist of direct borrowing and lending that circumvent the reserve requirements.

\section{Conclusion}

In many ways our results are similar to those from standard macro models with assumed demands for own-country currencies. Like them, our model suggests that the fundamental difference in floating and fixed exchange rate systems is in the monetary policies each system implies. And if standard models require present-value budget balance, they too recognize that at times changes in a country's monetary policy will require a change in its budget policy to maintain solvency. However, our analysis extends the standard analysis in two important ways.

First, our analysis provides an internal consistency lacking in the standard analysis. In a world of fiat monies there must be some type of friction to generate well-defined demands for owncountry currencies. But those frictions are then part of the economic environment which affect individual budget sets and so must show up in other aggregate demand schedules as well. Demand functions in standard analysis do not recognize the friction and hence likely are inconsistent with the economic environment they assume. In contrast, all demand functions in our analysis are consistent 
with there being frictions (reserve requirements) that generate the well-defined demands for fiat monies.

Second, unlike macro models our model permits determination of individual utilities. This feature is important in explaining a country's choice of regime.

Our analysis really goes only partway in explaining why a country at times would prefer to peg the value of its currency to that of another currency. The insight from our model is that since the major difference in regimes is in the monetary policies they imply and since different monetary policies imply different distributional effects, a country's choice of regime will depend on conditions that determine its distribution of agents across sectors. But this insight does not explain the commitment element to a fixed exchange rate system.

In our model the choice between floating and fixed exchange rates could be done each period. In particular at the beginning of each period the foreign country could decide whether to keep its $\beta^{*}$ unchanged (floating exchange rates) or to change it appropriately (fixed exchange rates). But an essential element of fixed exchange rates is a commitment to maintain the peg for many periods.

Our model suggests two reasons a country may want to commit to a fixed exchange rate for a number of periods. One is the constraint fixed exchange rates place on budget policy, as Rebelo (1994) discusses. Commitment does not allow a country to inflate more in order to finance an expanded government budget deficit, and so it constrains budget policy. This constraint can be seen operating in our second experiment. Under floating exchange rates, the monetary authority in the foreign country accommodates a higher budget deficit resulting from a higher interest expense, and so foreign budget policy need not be tightened. Under fixed exchange rates, the monetary authority does not fully accommodate, and so foreign budget policy must be tightened.

The second reason for commitment to a fixed exchange rate is that it may protect the interests of future generations. When current generations do not fully take into account the welfare of future 
generations, a period-by-period choice of policies will result in a monetary policy which is too easy in terms of social welfare. This principle is illustrated in our third experiment when the current voters choose floating exchange rates when a social planner would choose fixed exchange rates.

Our analysis also is only partly successful in explaining the choice of exchange rate regimes. At first glance it appears that we could extend our model to compare a common currency area arrangement with our floating and fixed rate systems. All that we would have to do is change the reserve requirements so that reserves could be held in any of the currencies of the countries in the area. However, our framework assumes complete information and no uncertainty, and so we cannot get at the costs of maintaining a common currency area. Those costs are due to imperfect information and the costs of monitoring. With incomplete information, individual countries have an incentive to cheat by printing more money and earning extra seignorage. Thus, all we can say is if those costs are high enough, the choice will come down to the two regimes we examine.

Incorporating uncertainty and private information would be useful, although difficult, extensions of the model. So too, would be an increase in the periods in an agent's life, as in the Auerbach and Kotlikoff model (AK 1987). This extension allows a period to be associated with a year and makes more straightforward the empirical verification of the model's implications.

We did not attempt to pursue the AK time period generalization, because we sought to generalize our model along other dimensions. First, unlike AK, ours has intragenerational borrowing and lending. We believe this is important for determining who gains and who loses under different exchange rate regimes. Second, while AK has no money, our model has separate monetary and budget policies, and the relationship between the two is crucial in understanding the requirements of maintaining fixed exchange rates (our second experiment). Third, we assume open economies with a world capital market, while AK assumes a closed economy. Obviously, AK is not suitable to examine trade issues. Finally, ours assumes both traded and nontraded goods, and this provides 
an important channel in our model for how policy changes are transmitted through changes in relative prices.

Our research strategy was to explore the implications of our assumptions in a tractable model. This required simplifying assumptions in many dimensions. It now would be worthwhile to see how much we could generalize our assumptions about production, uncertainty and information, and periods of time and still be able to solve the model. 


\section{Notes}

*The authors acknowledge helpful comments by Satyajit Chatterjee, Enrique Mendoza, and Richard Todd. The views expressed herein are those of the authors and not necessarily those of the Federal Reserve Bank of Minneapolis or the Federal Reserve System.

${ }^{1}$ Rebelo (1994) also explores the connection between exchange rate regimes and budget policies, but his model does not explicitly include money nor allow for the separation of monetary and budget policies.

${ }^{2}$ Several studies assume legal restrictions to analyze the effects of monetary policy, including Wallace (1983), Wallace (1984), Miller and Wallace (1985), and Miller and Todd (1995).

${ }^{3}$ In Miller and Todd (1995) there is an extended discussion of how these features and the model's economic environment lead to the model's policy implications.

${ }^{4}$ Unpleasant monetarist arithmetic was first described in Sargent and Wallace (1981).

${ }^{5} \mathrm{We}$ mean by symmetric that initially we chose parameter values which imply the home and foreign economies are identical. Our results would not be qualitatively changed had we assumed that the two economies differed only in scale (see Miller and Todd 1995).

${ }^{6}$ We note that solving $\pi^{F}(t-1)$ and $\pi^{F^{*}}(t-1)$ is equivalent to solving for $\mathrm{p}^{\mathrm{F}}(\mathrm{t})$ and $\mathrm{p}^{\mathrm{F}^{*}}(\mathrm{t})$ given their previous values. Thus, the first five market-clearing conditions depend on the price level. Since the difference in expected returns to residing in the two sectors depends on the rate of return on holding money, conditions (6) and (7) depend on the rate of inflation.

${ }^{7}$ As shown in Miller and Todd (1995), it is possible for the inflation rate to fall in the home country. Under some parameter values the rise in the base for the inflation tax implied by a rise in $\lambda$ generates more revenues than is required by the rise in $\rho$. A rise in $\lambda$ also can potentially lower the inflation rate in the foreign country if it results in a sufficiently higher level of $\mathrm{Q}^{*}$ and hence real foreign savings.

${ }^{8} \mathrm{We}$ extended the solution from 8 to 30 periods to make certain there was no convergence to a new steady state. When $\beta$ is increased as in experiment 1 , the foreign country also must change 
its $\beta^{*}$ to effect a new $\rho-\mathrm{p}^{\mathrm{F}^{*}}(1)$ pair. However, when it is responding with $\beta^{*}$ to a change in $\beta$, it can effect a new pair consistent with equilibrium. When it is responding with $\beta^{*}$ to a change in $\lambda$, it cannot. 


\section{References}

Auerbach, A.J. and L.J. Kotlikoff, 1987, Dynamic fiscal policy (Cambridge University Press, Cambridge, Mass.)

Frenkel, J.A. and M.L. Mussa, 1985, Asset markets, exchange rates and the balance of payments, in: R.W. Jones and P.B. Kenan, eds., Handbook of international economics, Vol. 2 (NorthHolland Amsterdam) 679-747.

Miller, P.J. and R.M. Todd, 1992, Real effects of monetary policy in a world economy, Research Department Staff Report 154, Federal Reserve Bank of Minneapolis. , 1995, Real effects of monetary policy in a world economy, Journal of Economic Dynamics and Control 19 (Jan./Feb.): 125-53.

Miller, P.J. and N. Wallace, 1985, International coordination of macroeconomic policies: A welfare analysis, Federal Reserve Bank of Minneapolis Quarterly Review 9 (Spring): 14-32.

Rebelo, S., 1994, What happens when countries peg their exchange rates? (The real side of monetary reforms), Manuscript, University of Rochester.

Sargent, T.J. and N. Wallace, 1981, Some unpleasant monetarist arithmetic, Federal Reserve Bank of Minneapolis Quarterly Review 5 (Fall): 1-17.

Wallace, N., 1983, A legal restrictions theory of the demand for "money" and the role of monetary policy, Federal Reserve Bank of Minneapolis Quarterly Review 7 (Winter): 1-7. , 1984, Some of the choices for monetary policy, Federal Reserve Bank of Minneapolis Quarterly Review 8 (Winter): 15-24. 
Table 1

Young Vote

\begin{tabular}{lll}
\hline & & \multicolumn{1}{c}{ Criterion } \\
\cline { 3 - 3 } Type & Number & $\begin{array}{l}\text { Vote for Fixed Exchange Rates } \\
\text { If and Only If }\end{array}$ \\
\hline Farmers & $\mathrm{n}^{*}(1)$ & $\mathrm{U}\left(\mathrm{c}(1)_{\mathrm{F}}^{* \prime}\right)>\mathrm{U}\left(\mathrm{c}(1)_{\mathrm{F}}^{*}\right)$ \\
Service Producers & $1-\mathrm{n}^{*}(1)$ & $\mathrm{U}\left(\mathrm{c}(1)_{\mathrm{S}}^{* *}\right)>\mathrm{U}\left(\mathrm{c}(1)_{\mathrm{S}}^{*}\right)$ \\
\hline
\end{tabular}


Table 2

Old Vote

\begin{tabular}{lll}
\hline & & \multicolumn{1}{c}{ Criterion } \\
\cline { 3 - 3 } Type & Number & $\begin{array}{l}\text { Vote for Fixed Exchange Rates } \\
\text { If and Only If }\end{array}$ \\
\hline Farmers & $\mathrm{n}^{*}(0)$ & $\mathrm{Q}(1)^{* \prime}<\mathrm{Q}(1)^{*}$ and $\mathrm{p}^{\mathrm{F}}(1)^{* \prime}>\mathrm{p}^{\mathrm{F}(1)^{*}}$ \\
Service Producers & $1-\mathrm{n}^{*}(0)$ & $\begin{array}{l}{\left[\mathrm{c}_{\mathrm{F}}^{\mathrm{F}}(0)^{* \prime}+\mathrm{c}_{\mathrm{S}}^{\mathrm{F}}(0)^{* \prime}\right]>\left[\mathrm{c}_{\mathrm{F}}^{\mathrm{F}}(0)^{*}+\mathrm{c}_{\mathrm{S}}^{\mathrm{F}}(0)^{*}\right]} \\
\text { and } \\
\end{array}$ \\
& & {$\left[\mathrm{c}_{\mathrm{F}}^{\mathrm{S}}(0)^{* \prime}+\mathrm{c}_{\mathrm{S}}^{\mathrm{S}}(0)^{* *}\right]>\left[\mathrm{c}_{\mathrm{F}}^{\mathrm{S}}(0)^{*}+\mathrm{c}_{\mathrm{S}}^{\mathrm{S}}(0)^{*}\right]$} \\
\hline
\end{tabular}


Table 3

Choice of Exchange Rate System

$$
B=B^{*}=30.0
$$

\begin{tabular}{llrl}
\hline \multicolumn{1}{c}{ Type } & \multicolumn{1}{c}{ Criteria: $>\Rightarrow$ Preferred } & Floating & \multicolumn{1}{c}{ Fixed } \\
\hline Old Farmers & $\left\{\begin{array}{l}1 / \mathrm{Q}(1)^{*} \\
\mathrm{p}^{\mathrm{F}}(1)^{*}\end{array}\right.$ & $\left.\begin{array}{l}1.01316 \\
1.06066\end{array}\right\}$ & $>\left\{\begin{array}{l}1.01288 \\
1.05628\end{array}\right.$ \\
Old Service Prod. & $\left\{\begin{array}{l}\text { Old consumption of food } \\
\text { Old consumption of services }\end{array}\right.$ & $\left.\begin{array}{r}49.06165 \\
49.70717\end{array}\right\}$ & $<\left\{\begin{array}{l}49.09955 \\
49.73191\end{array}\right.$ \\
& $\mathrm{U}\left(\mathrm{c}(1)_{\mathrm{F}}^{*}\right)$ & 7.73144 & $>7.73085$ \\
Young Farmers & $\mathrm{U}\left(\mathrm{c}(1)_{\mathrm{S}}^{*}\right)$ & 7.73206 & $<7.73299$ \\
Young Service Prod. & $\mathrm{U}^{\mathrm{sS}}$ & 7.731716 & $>7.731703$ \\
& & .4985 & $=.4985$ \\
\hline
\end{tabular}

Voting percentage for fixed exchange rates: $50.151 \%$

Social planner chooses floating exchange rates. 
Table 4

$B=B^{*}=31.0$

\begin{tabular}{|c|c|c|c|c|}
\hline Type & Criteria: $>\Rightarrow$ Preferred & Floating & & Fixed \\
\hline Old Farmers & $\left\{\begin{array}{l}1 / \mathrm{Q}(1) * \\
\mathrm{p}^{\mathrm{F}}(1) *\end{array}\right.$ & $\left.\begin{array}{l}1.00266 \\
1.05387\end{array}\right\}$ & $>$ & $\left\{\begin{array}{l}1.00239 \\
1.04947\end{array}\right.$ \\
\hline Old Service Prod. & $\left\{\begin{array}{l}\text { Old consumption of food } \\
\text { Old consumption of services }\end{array}\right.$ & $\left.\begin{array}{l}49.27807 \\
49.40924\end{array}\right\}$ & $<$ & $\left\{\begin{array}{l}49.40924 \\
49.43440\end{array}\right.$ \\
\hline Young Farmers & $\mathrm{U}\left(\mathrm{c}(1)_{\mathrm{F}}^{*}\right)$ & 7.73784 & $>$ & 7.73725 \\
\hline \multirow[t]{2}{*}{ Young Service Prod. } & $\mathrm{U}\left(\mathrm{c}(1)_{S}^{*}\right)$ & 7.73845 & $<$ & 7.73941 \\
\hline & $\mathrm{U}^{\mathrm{SS}}$ & 7.738114 & $>$ & 7.738109 \\
\hline $\mathrm{n}^{*}(0)=\mathrm{n}^{*}(1)$ & & .50003 & $=$ & .50003 \\
\hline
\end{tabular}

Voting percentage for fixed exchange rates: $49.997 \%$

Social planner chooses floating exchange rates. 


\section{Table 5}

$$
B=B^{*}=32.0
$$

\begin{tabular}{llrl}
\hline Type & \multicolumn{1}{c}{ Criteria: $>\Rightarrow$ Preferred } & Floating & \multicolumn{1}{c}{ Fixed } \\
\hline Old Farmers & $\left\{\begin{array}{l}1 / \mathrm{Q}(1) * \\
\mathrm{p}^{\mathrm{F}}(1) *\end{array}\right.$ & $\left.\begin{array}{r}.99246 \\
1.04713\end{array}\right\}$ & $>\left\{\begin{array}{r}.99217 \\
1.04271\end{array}\right.$ \\
& & & \\
Old Service Prod. & $\left\{\begin{array}{l}\text { Old consumption of food } \\
\text { Old consumption of services }\end{array}\right.$ & $\left.\begin{array}{r}49.49257 \\
49.11912\end{array}\right\}$ & $<\left\{\begin{array}{l}49.53242 \\
49.14470\end{array}\right.$ \\
Young Farmers & $\mathrm{U}\left(\mathrm{c}(1)_{\mathrm{F}}^{*}\right)$ & 7.74415 & $>7.74356$ \\
Young Service Prod. & $\mathrm{U}\left(\mathrm{c}(1)_{\mathrm{S}}^{*}\right)$ & 7.74476 & $<7.74574$ \\
& $\mathrm{U}^{\mathrm{SS}}$ & 7.744427 & $<7.744429$ \\
$\mathrm{n}^{*}(0)=\mathrm{n}^{*}(1)$ & & .50151 & $=.50151$ \\
\hline
\end{tabular}

Voting percentage for fixed exchange rates: $49.850 \%$ Social planner chooses fixed exchange rates. 